\title{
Mild Cognitive Impairment and Receipt of Treatments for Acute Myocardial Infarction in Older Adults
}

\author{
Deborah A. Levine, MD, $M P H^{1,2,3}$, Kenneth M. Langa, MD, $P h D^{1,3,4,5}$, \\ Andrej Galecki, MD, PhD ${ }^{1,6}$, Mohammed Kabeto, MS ${ }^{7}$, Lewis B. Morgenstern, MD2, \\ Darin B. Zahuranec, MD, MS ${ }^{2}$, Bruno Giordani, $P h D^{7}$, Lynda D. Lisabeth, $P h D^{2,8}$, and \\ Brahmajee K. Nallamothu, MD, $\mathrm{MPH}^{1,3,4}$
}

\begin{abstract}
'Department of Internal Medicine, University of Michigan (U-M), Ann Arbor, MI, USA; ${ }^{2}$ Department of Neurology and Stroke Program, U-M, Ann Arbor, MI, USA; ${ }^{3}$ Institute for Healthcare Policy and Innovation, U-M, Ann Arbor, MI, USA; ${ }^{4}$ VA Ann Arbor Healthcare System, Ann Arbor, MI, USA; ${ }^{5}$ Institute for Social Research, U-M, Ann Arbor, MI, USA; ${ }^{6}$ Department of Biostatistics, U-M, Ann Arbor, MI, USA; ${ }^{7}$ Department of Psychiatry \& Michigan Alzheimer's Disease Center, U-M, Ann Arbor, MI, USA; ${ }^{8}$ Department of Epidemiology, U-M, Ann Arbor, MI, USA.
\end{abstract}

BACKGROUND: Older adults with mild cognitive impairment (MCI) should receive evidence-based treatments when indicated. Providers and patients may overestimate the risk of dementia in patients with MCI leading to potential under-treatment. However, the association between pre-existing MCI and receipt of evidence-based treatments is uncertain.

OBJECTIVE: To compare receipt of treatments for acute myocardial infarction (AMI) between older adults with pre-existing MCI and cognitively normal patients.

DESIGN: Prospective study using data from the nationally representative Health and Retirement Study, Medicare, and American Hospital Association.

PARTICIPANTS: Six hundred nine adults aged 65 or older hospitalized for AMI between 2000 and 2011 and followed through 2012 with pre-existing MCI (defined as modified Telephone Interview for Cognitive Status score of 7-11) and normal cognition (score of 12-27).

MAIN MEASURES: Receipt of cardiac catheterization and coronary revascularization within 30 days and cardiac rehabilitation within 1 year of AMI hospitalization.

KEY RESULTS: Among the survivors of AMI, 19.2\% had pre-existing MCI (55.6\% were women and 44.4\% were male, with a mean [SD] age of 82.3 [7.5] years), and $80.8 \%$ had normal cognition $(45.7 \%$ were women and $54.3 \%$ were male, with a mean age of 77.1 [7.1] years). Survivors of AMI with pre-existing MCI were significantly less likely than those with normal cognition to receive cardiac catheterization (50\% vs 77\%; $P<0.001$ ), coronary revascularization $(29 \%$ vs $63 \% ; P<0.001)$, and cardiac rehabilitation ( $9 \%$ vs $22 \% ; P=0.001)$ after AMI. After adjusting for patient and hospital factors, pre-existing MCI remained associated with lower use of cardiac catheterization (adjusted hazard ratio (aHR), 0.65; 95\% CI,

Prior presentations: This paper was presented as an oral abstract at the 2018 Society of General Internal Medicine Conference, April 12, 2018, Denver, $\mathrm{CO}$.

Electronic supplementary material The online version of this article (https://doi.org/10.1007/s11606-019-05155-8) contains supplementary material, which is available to authorized users.

Received October 15, 2018

Revised February 27, 2019

Accepted May 1, 2019

Published online August 13, 2019
0.48-0.89; $P=0.007$ ) and coronary revascularization (aHR, 0.55; 95\% CI, 0.37-0.81; $P=.003$ ), but not cardiac rehabilitation (aHR, 1.01; 95\% CI, 0.49-2.07; $P=0.98$ ).

CONCLUSIONS: Pre-existing MCI is associated with lower use of cardiac catheterization and coronary revascularization but not cardiac rehabilitation after AMI.

KEY WORDS: aging; Alzheimer's; cardiovascular disease; health services research.

J Gen Intern Med 35(1):28-35

DOI: $10.1007 / \mathrm{s} 11606-019-05155-8$

(C) Society of General Internal Medicine 2019

\section{INTRODUCTION}

Up to 1 in 5 adults and more than 5.4 million Americans $\geq$ 65 have mild cognitive impairment (MCI), ${ }^{1}$ and this number is projected to triple by $2050 .^{2} \mathrm{MCI}$, a symptomatic clinical stage on the continuum of cognitive decline between normal cognition and dementia, is characterized by measurable cognitive impairment that does not severely affect daily functioning. ${ }^{3,4}$ Although dementia worsens over time in nearly all patients, ${ }^{5,6} \mathrm{MCI}$ does not inevitably progress to dementia, ${ }^{7}$ even after a decade. ${ }^{8}{ }^{8}$ Many older adults with MCI live years ${ }^{10}$ - an average of 9 years in one community-based study ${ }^{11}$ - with good quality of life, ${ }^{12,} 13$ and so face competing health risks of aging, particularly cardiovascular disease (CVD). ${ }^{11} \mathrm{CVD}$ is the leading cause of death and serious morbidity in community-dwelling older adults with and without MCI. ${ }^{11,}{ }^{14}$ Although it is known that patients with dementia are less likely than cognitively normal patients to receive established, effective treatments for $\mathrm{CVD},{ }^{15}, 16$ it is unknown whether patients with pre-existing MCI get fewer effective treatments for CVD.

Acute myocardial infarction (AMI) is the most common CVD event. ${ }^{14,}{ }^{17}$ Several treatments after AMI reduce mortality, morbidity, and disability and increase quality of life. ${ }^{18,19}$ Large, randomized, controlled trials and meta-analyses have shown that both early cardiac catheterization with appropriate 
coronary revascularization $^{20-22}$ and cardiac rehabilitation ${ }^{23,24}$ reduce mortality and improve physical function after AMI. Current clinical guidelines ${ }^{25}$ recommend that all vulnerable elders, except those with advanced dementia or limited life expectancy, receive these effective treatments. It is unknown whether patients with pre-existing MCI are less likely than patients with normal cognition to receive invasive therapies like cardiac catheterization and revascularization, or postacute, non-invasive services like cardiac rehabilitation, after AMI.

Leveraging a nationally representative sample of US older adults with repeated objective measures of cognition, we conducted an observational cohort study to determine the extent to which patients with pre-existing MCI were less likely than cognitively normal patients to receive established, effective treatments after AMI, and whether treatment differences persisted after adjusting for patient and hospital factors.

\section{METHODS}

\section{Study Population}

The Health and Retirement Study (HRS) is a nationally representative longitudinal study of 37,000 US adults $\geq 51$ evaluating health and economic changes associated with aging. ${ }^{26}$ The HRS samples from all contiguous US states, with oversampling of Blacks and Hispanics. Every 2 years since 1992, HRS participants have been interviewed using standard instruments. The interviews are conducted by trained survey interviewers at the Institute for Social Research at the University of Michigan. The HRS achieves a high follow-up rate, ranging 85-91\% from 1998 to 2012 including proxies ${ }^{26}$ and follows participants into nursing homes. Utilization and dates of inpatient and outpatient medical services were available from the Centers for Medicare and Medicaid Services (CMS) (years 19912012) for HRS participants who are enrolled in Medicare fee-for-service (at age 65 or disability) and consent to this linkage (80-90\% consent). The research protocol was approved by the University of Michigan Institutional Review Board and all human participants gave written informed consent.

We identified 1,119 HRS participants $\geq 65$ hospitalized for AMI between January 1, 2000 and December 31, 2011 using valid International Classification of Diseases-Ninth (ICD-9) Revision-CM codes (410.xx except 410.x2 as the primary discharge diagnosis) ${ }^{18}$ and interviewed by HRS in 1995 or later. Of these, 510 were excluded because of ineligibility for process measures or incomplete information on hospital characteristics (Online Appendix 1 and 2). The study sample included 609 participants hospitalized for AMI, 117 (19.2\%) of whom were classified as having pre-existing MCI.

\section{Measurement of AMI Process Measures}

We evaluated three process measures using valid ICD-9 and Current Procedural Terminology $\operatorname{codes}^{27}$ to capture different aspects of post-AMI care: (1) cardiac catheterization $\leq 30$ days to evaluate the threshold for invasive diagnostic testing; (2) coronary revascularization (percutaneous coronary intervention $[\mathrm{PCI}]$ or coronary artery bypass graft surgery $[\mathrm{CABG}]) \leq$ 30 days to evaluate the threshold for invasive treatments; and (3) cardiac rehabilitation $\leq 365$ days to evaluate the use of post-acute, non-invasive services (Online Appendix 3). Cardiac rehabilitation had a longer time window based on Medicare Part B coverage. ${ }^{28}$

\section{Measurement of Cognition and Other Study Variables}

Trained HRS interviewers administered cognitive function tests biennially in-person or by telephone using the Modified Telephone Interview for Cognitive Status (TICS-m), a global cognition test patterned after the Mini-Mental State Examination. ${ }^{29,} 30$ The TICS-m assesses global cognition, learning, and memory (scores range, 0-27). Higher scores indicate better performance. Among older adults, telephone measurement of global cognition, learning, and memory, compared to inperson measurement, is comparable, reliable, and precise. ${ }^{31}$, ${ }^{32}$ The TICS-m is validated as a cognitive screening instrument and designed for use in population-based studies. ${ }^{29}, 30$ Proxy respondents had separate assessments. At each interview, the HRS participant was classified as having normal cognition, MCI, or dementia using methods and validated cutpoints ${ }^{33,34}$ based on in-depth, in-home, neuropsychological, and clinical assessments as well as expert clinician adjudication from the Aging, Demographics, and Memory Study, an HRS dementia sub-study. ${ }^{32}$

Patient and hospital factors were based on determinants affecting treatment of older patients with serious illness $(\text { Table } 1)^{35}$ and included functional limitations in basic and instrumental activities of daily living (ADL/IADL), depressive symptoms, and social support/structure. ${ }^{36-38}$ Dates of death were available for $>95 \%$ of participants from the National Death Index and CMS. Hospital characteristics were available from the American Hospital Association (Online Appendix 1).

\section{Statistical Analysis}

We followed a pre-specified analysis plan (Online Appendix 1). We performed descriptive and bivariate statistics. To estimate the relationship of pre-existing MCI to time-to-receipt of the process measures, we used Cox proportional regression models (M0). Results are presented as hazard ratios before and after adjustment for patient and hospital factors.

We also examined whether receipt of coronary revascularization (primary process measure) reduced the association between MCI and death (main outcome of interest). First, we fitted two additional multivariable Cox models for 
Table 1 Participant and Hospital Characteristics by Cognitive Status: Health and Retirement Study-Medicare, 2000-2012

\begin{tabular}{|c|c|c|c|}
\hline & $\begin{array}{l}\text { Participants with normal cognition } \\
(n=492)\end{array}$ & $\begin{array}{l}\text { Participants with pre-existing MCI } \\
(n=117)\end{array}$ & $P$ value \\
\hline \multicolumn{4}{|l|}{ Participant characteristics } \\
\hline Age at AMI, mean (SD), years & $77.1(7)$ & $82.3(7)$ & $<0.001$ \\
\hline Women & $225(46)$ & $65(56)$ & 0.056 \\
\hline \multicolumn{3}{|l|}{ Race/ethnicity } & 0.001 \\
\hline Non-Hispanic White & $435(88)$ & $86(74)$ & \\
\hline Non-Hispanic Black & $29(6)$ & $16(14)$ & \\
\hline Hispanic & $20(4)$ & $12(10)$ & \\
\hline Other & $8(2)$ & $3(3)$ & \\
\hline \multicolumn{3}{|l|}{ Marital status/living arrangement } & 0.07 \\
\hline Married/partner & $293(60)$ & $56(48)$ & \\
\hline Unmarried/living with other & $60(12)$ & 19 (16) & \\
\hline Unmarried/living alone & $139(28)$ & $42(36)$ & \\
\hline \multicolumn{3}{|l|}{ Education } & $<0.001$ \\
\hline$<12$ years & $114(23)$ & $67(57)$ & \\
\hline 12 years & $207(42)$ & $34(29)$ & \\
\hline $13-15$ years & $92(19)$ & $12(10)$ & \\
\hline$\geq 16$ years & 79 (16) & $4(3)$ & \\
\hline \multicolumn{3}{|l|}{ Net wealth (quartiles) } & 0.003 \\
\hline$\leq \$ 51,200$ & $115(23)$ & $43(37)$ & \\
\hline$\$ 51,201-\$ 147,000$ & $115(23)$ & $33(28)$ & \\
\hline$\$ 147,001-\$ 356,000$ & $135(27)$ & 19 (16) & \\
\hline$>\$ 356,000$ & $127(26)$ & $22(19)$ & \\
\hline \multicolumn{3}{|l|}{ Income (quartiles) } & 0.001 \\
\hline$\leq \$ 15,580$ & $110(22)$ & $44(38)$ & \\
\hline$\$ 15,581-\$ 26,760$ & $127(26)$ & $31(27)$ & \\
\hline$\$ 26,761-\$ 45,980$ & $124(25)$ & $26(22)$ & \\
\hline$>\$ 45,980$ & $131(27)$ & $16(14)$ & \\
\hline $\begin{array}{l}\text { Charlson comorbidity index score, mean (SD), } \\
\text { points }\end{array}$ & $2.9(2)$ & $3.0(2)$ & 0.69 \\
\hline \multicolumn{3}{|l|}{ CES-D depressive symptoms } & $<0.001$ \\
\hline 0 & $192(39)$ & $31(27)$ & \\
\hline $1-4$ & $267(54)$ & $66(56)$ & \\
\hline $5-8$ & $33(7)$ & $20(17)$ & \\
\hline Functional limitations, mean (SD), number & 0.7 (1) & $1.7(2)$ & $<0.001$ \\
\hline \multicolumn{4}{|l|}{ Geographic proximity to adult children } \\
\hline No children or missing & $36(7)$ & $16(14)$ & \\
\hline Co-residence & $88(18)$ & $21(18)$ & \\
\hline Within 10 miles & $214(44)$ & $56(48)$ & \\
\hline Greater than 10 miles & $154(31)$ & $24(21)$ & \\
\hline Have an adult daughter & $395(80)$ & $84(72)$ & 0.04 \\
\hline \multicolumn{4}{|l|}{ Hospital characteristics } \\
\hline Medical school affiliate or teaching hospital & $225(46)$ & $48(41)$ & 0.36 \\
\hline \multicolumn{3}{|l|}{ Region } & 0.47 \\
\hline Northeast & $81(16)$ & $19(16)$ & \\
\hline Midwest & $214(44)$ & $58(50)$ & \\
\hline South & $132(27)$ & $30(26)$ & \\
\hline West & $65(13)$ & $10(9)$ & \\
\hline \multicolumn{3}{|l|}{ Bed size } & 0.012 \\
\hline$<200$ beds & $126(26)$ & $46(39)$ & \\
\hline $200-399$ beds & $183(37)$ & $36(31)$ & \\
\hline$\geq 400$ beds & $183(37)$ & $35(30)$ & \\
\hline \multicolumn{3}{|l|}{ Authority type } & 0.72 \\
\hline Government nonfederal & $34(7)$ & $6(5)$ & \\
\hline Not for profit & $372(76)$ & $92(79)$ & \\
\hline For profit & $86(17)$ & 19 (16) & \\
\hline
\end{tabular}

Functional limitations were measured by summing the number of difficulties with 6 activities of daily living (walking, dressing, bathing, eating, getting in/out of bed, using toilet), and 5 instrumental activities of daily living (managing money, taking medication, preparing hot meals, using phones, and shopping for groceries) (range, 0-11). Depressive symptoms were measured by the 8-item Center for Epidemiological Studies Depression Scales. Social support/structure was measured by marital status/living arrangement, having a daughter, and geographic proximity of adult children. $P$ values were calculated using chi-square test for categorical variables and t test for continuous variables. Patient characteristics were available from the Health and Retirement Study. Hospital characteristics were available from the American Hospital Association

MCI mild cognitive impairment, AMI acute myocardial infarction, CES-D Center for Epidemiological Studies Depression Scale, SD standard deviation

time to death (M1 and M2). Both models included the same set of patient and hospital factors as covariates. The only difference between the two models is that the receipt of process measure covariate is included in model M2. We then assessed the reduction of the MCI direct effect by adding receipt of the process measure covariate in model
M2 relative to the total effect in model M1. Such reduction of the total effect implies that the effect of MCI on mortality is partially mediated by receipt of the process measure. We also performed formal mediation analysis ${ }^{39,} 40$ to confirm that receipt of coronary revascularization mediates the association between MCI and death. 


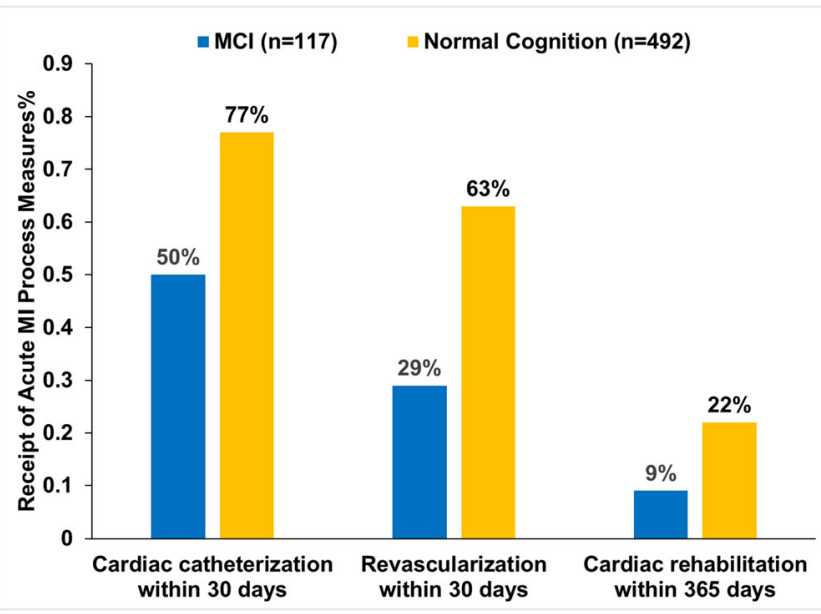

Figure 1 Differences in receipt of process measures for acute myocardial infarction in older adults by cognitive status: Health and Retirement Study-Medicare, 2000-2012. All $P \leq 0.001$. Data sources: Health and Retirement Study, Medicare, American Hospital Association, 2000 to 2012. The percentages of receipt of process measures by cognitive status are unadjusted. Please see Table 2 for the unadjusted and adjusted hazard ratios for receipt of process measures by pre-existing cognitive status.

We used multiple imputation for missing depressive symptoms $(n=37)$ using all available prior depressive symptom scores. An analyst (MK) performed analyses under the supervision of the biostatistician (AG). MK had full access to all the data in the study and takes responsibility for its integrity and the data analysis. All statistical analyses were performed with the STATA software, version 15.0.

\section{Sensitivity Analysis}

We examined receipt of the process measures at different time intervals ( 30 days, 90 days, and 365 days). To test the robustness of our findings, we repeated analyses after excluding

Table 2 Unadjusted and Adjusted Hazard Ratios and 95\% Confidence Intervals for Receipt of Process Measures for Acute Myocardial Infarction by Pre-existing Cognitive Status (Mild Cognitive Impairment Versus Normal Cognition) in Older Adults $(n=609)$ : Health and Retirement Study-Medicare, 2000-2012

\begin{tabular}{|c|c|c|c|c|}
\hline Process measures & $\begin{array}{l}\text { Unadjusted } \\
\text { hazard ratios } \\
\text { (95\% CI) for } \\
\text { MCI vs. } \\
\text { normal } \\
\text { cognition }\end{array}$ & $\begin{array}{l}P \\
\text { value }\end{array}$ & $\begin{array}{l}\text { Adjusted } \\
\text { hazard } \\
\text { ratios (95\% } \\
\text { CI) for } \\
\text { MCI vs. } \\
\text { normal } \\
\text { cognition }\end{array}$ & $\begin{array}{l}P \\
\text { value }\end{array}$ \\
\hline $\begin{array}{l}\text { Cardiac } \\
\text { catheterization } \\
\text { within } 30 \text { days }\end{array}$ & $\begin{array}{l}0.45(0.34- \\
0.59)\end{array}$ & $\begin{array}{l}< \\
0.001\end{array}$ & $\begin{array}{l}0.65(0.48- \\
0.89)\end{array}$ & 0.007 \\
\hline $\begin{array}{l}\text { Coronary } \\
\text { revascularization } \\
\text { within } 30 \text { days }\end{array}$ & $\begin{array}{l}0.35(0.24- \\
0.50)\end{array}$ & $\begin{array}{l}< \\
0.001\end{array}$ & $\begin{array}{l}0.55(0.37- \\
0.81)\end{array}$ & 0.003 \\
\hline $\begin{array}{l}\text { Cardiac } \\
\text { rehabilitation } \\
\text { within } 365 \text { days }\end{array}$ & $\begin{array}{l}0.36(0.19- \\
0.69)\end{array}$ & 0.002 & $\begin{array}{l}1.01(0.49- \\
2.07)\end{array}$ & 0.98 \\
\hline
\end{tabular}

Adjusted for patient factors (age, sex, ethnicity, marital status, education, income, wealth, functional limitations, comorbidity score, depressive symptoms, social support) and hospital factors (teaching status, region, bed size, and hospital type)

MCI mild cognitive impairment individuals classified as MCI by the HRS but having dementia/Alzheimer's disease based on Medicare claims and also after excluding individuals classified as MCI and having $\geq 2$ IADLs because these people may have more severe cognitive impairment or dementia. To determine the effect of mortality on the association between pre-existing $\mathrm{MCI}$ and receipt of the process measures, we repeated analyses after excluding individuals who died during the time interval for receipt of process measures and adding those who died $\leq 7$ days of hospital discharge. To examine whether AMI type (ST-elevation MI versus non-ST-elevation MI) modified the effect of preexisting MCI on receipt of the process measures, we introduced AMI type and a pre-existing MCI-by-AMI type interaction term to the fully adjusted models (ICD-9 code for NSTEMI 410.71 and remaining codes for STEMI). ${ }^{18,}{ }^{41}$ To control for possible temporal decreases in coronary revascularization for $\mathrm{AMI},{ }^{42}$ we repeated the analysis adding year of AMI hospitalization to the regression models.

\section{RESULTS}

Table 1 presents patient characteristics. Among the patients with pre-existing $\mathrm{MCI}$, the median time between the cognitive assessment of MCI and the AMI hospitalization was 403 days (interquartile range, 205-628 days). We compared characteristics between included and excluded participants (Online Appendix 4). Most patients received cardiac catheterization $(70 \%)$ and coronary revascularization $(54 \%) \leq 1$ week of their

Table 3 Effects of Pre-existing Mild Cognitive Impairment on 1Year Mortality (Primary Clinical Outcome) and Mediation (Indirect) Effect of Receipt of Coronary Revascularization Within 30 Days (Primary Process Measure) on the Relationship Between Pre-existing Mild Cognitive Impairment and 1-Year Mortality in Older Adults with Acute Myocardial Infarction $(n=609)$ Using Cox Regression: Health and Retirement Study-Medicare, 2000-2012

\begin{tabular}{llll}
\hline \hline $\begin{array}{l}\text { Dependent variable } \\
\text { (model label) }\end{array}$ & Main predictor(s) & $\begin{array}{l}\text { Adjusted } \\
\text { hazard } \\
\text { ratio (95\% } \\
\text { CI) }\end{array}$ & $\begin{array}{l}\boldsymbol{P} \\
\text { value }\end{array}$ \\
\hline Time to death (M1) & MCI & $2.45(1.55-$ & $<$ \\
& & $3.85)$ & 0.001 \\
Time to coronary & MCI & $0.55(0.37-$ & 0.003 \\
revascularization & & $0.81)$ & \\
within 30 days (M0) & MCI & $2.14(1.36-$ & 0.001 \\
Time to death (M2) & Coronary & $3.37)$ & $0.42(0.26-$ \\
& $\begin{array}{l}\text { revascularization } \\
\text { within 30 days }\end{array}$ & $0.68)$ & 0.001 \\
& & & \\
\hline
\end{tabular}

Adjusted for patient factors (age, sex, ethnicity, marital status, education, income, wealth, functional limitations, comorbidity score, depressive symptoms, social support) and hospital factors (teaching status, region, bed size, and hospital type). Model MO is a Cox proportional regression model for time to receipt of coronary revascularization within 30 days after adjusting for pre-existing cognitive status, patient factors, and hospital factors. Model M1 is a Cox proportional regression model with for time to death after adjusting for pre-existing cognitive status, patient factors, and hospital factors. Model M2 added receipt of coronary revascularization within 30 days to model M1

MCI mild cognitive impairment 
hospitalization. The median time to initiation of cardiac rehabilitation was 47 days (interquartile range, 30-87).

Older adults with pre-existing MCI were less likely than those with normal cognition to receive cardiac catheterization (50\% vs. $77 \% ; P<0.001$; unadjusted hazard ratio [HR], 0.45 [95\% CI, 0.34-0.59]) and coronary revascularization (29\% vs. $63 \% ; P<0.001 ; \mathrm{HR}, 0.35$ [95\% CI, 0.24-0.50]) within 30 days, and cardiac rehabilitation within 365 days following AMI (9\% vs. $22 \% \%$; $P=0.001$; HR, 0.36 [95\% CI, 0.19 0.69]) (Fig. 1 and Table 2).

After adjusting for patient and hospital factors, patients with pre-existing MCI, compared to those with normal cognition, were significantly less likely to receive cardiac catheterization (adjusted HR [aHR], 0.65; 95\% CI, 0.48-0.89) and coronary revascularization (aHR, 0.55; 95\% CI, 0.37-0.81), but not cardiac rehabilitation (aHR, 1.01; 95\% CI, 0.49-2.07) after AMI (Table 2). Results were similar in analyses that measured process measures $\leq 90$ days after AMI hospitalization (Online Appendix 5).

We also examined whether receipt of coronary revascularization reduced the association between MCI and death. Of the 609 individuals, $114(18.7 \%)$ died $\leq 1$ year after AMI hospitalization. There were 45 deaths in 117 patients with MCI (38.5\%) and 69 deaths in 492 patients with normal cognition (14\%) within 1 year after AMI hospitalization. Pre-existing MCI was associated with increased risk of mortality (aHR, 2.45; 95\% CI, 1.55-3.85) (model M1, Table 3). With further adjustment for receipt of coronary revascularization, the risk of mortality associated with MCI decreased (aHR, 2.14; 95\% CI, 1.36-3.37) (model M2, Table 3). Formal mediation analysis confirmed that receipt of coronary revascularization mediated the positive association between pre-existing MCI and mortality (the effect tested using the Sobel test was significant $[P=0.02]$ ) (Online Appendix 6).

\section{Sensitivity Analyses}

Results were similar in analyses including AMI type (STEMI vs NSTEMI), and AMI type did not modify the effect of preexisting MCI on receipt of process measures ( $P$ for MCI-byAMI type interaction term was 0.62 for cardiac catheterization, 0.80 for coronary revascularization, and 0.82 for cardiac rehabilitation) (Online Appendix 7). Results were similar in analyses that controlled for temporal trends in coronary revascularization, excluded individuals who died during the time interval for receipt of process measures, excluded individuals classified as MCI based on HRS data but having dementia/ Alzheimer's disease based on CMS data, and excluded individuals classified as MCI and having $\geq 2$ IADL limitations (Online Appendix 8). Patients in the study sample, compared to those who died $\leq 7$ days of AMI hospitalization $(n=79)$, had less MCI (19\% vs. $29 \% ; P=0.04)$ and were more likely to receive cardiac catheterization $(70 \%$ vs. $34 \% ; P<0.001)$ and coronary revascularization $\leq 7$ days ( $54 \%$ vs. $22 \% ; P<0.001$ ). Results were consistent after adding the patients who died $\leq$ 7 days of hospital discharge (Online Appendix 9).

\section{DISCUSSION}

We found that patients with pre-existing MCI were less likely than cognitively normal patients to receive three process measures following AMI. The effect sizes were large with absolute differences of $27 \%$ for cardiac catheterization, $34 \%$ for coronary revascularization, and $13 \%$ for cardiac rehabilitation. After adjusting for patient and hospital factors, older adults with pre-existing MCI, compared to those with normal cognition, were significantly less likely to receive cardiac catheterization-35\% less likely - and coronary revascularization- $45 \%$ less likely. In contrast, our results suggest that differences in patient (age, comorbidity, and functional limitations) and hospital factors explain differences in receipt of cardiac rehabilitation between patients with $\mathrm{MCI}$ and cognitively normal patients. Results were similar in analyses that accounted for AMI type (STEMI vs NSTEMI) and there was no evidence that AMI type modified the association between pre-existing MCI and receipt of the process measures for AMI.

Compared to the elderly with dementia, less is known about the quality of AMI care in the larger population of older adults with MCI. Not only are patients with dementia less likely to be treated intensively for $\mathrm{AMI}^{15,16}$ but even among patients with dementia, older age and lower cognitive status are associated with reduced use of invasive procedures (cardiac catheterization and $\mathrm{PCI}$ ) for $\mathrm{AMI} .{ }^{43}$ To our knowledge, our study is the first investigation to extend these findings to those with preexisting MCI. A previous study found that older adults with MCI measured 1 month after AMI were less likely to receive AMI process measures; however, results were not adjusted for confounding factors (e.g., patient and hospital factors) and MCI might not have preceded the AMI (i.e., the AMI might have caused or contributed to the MCI). ${ }^{44}$

It is unknown whether patients with MCI get fewer invasive treatments for AMI because of patient and care partner preferences or physician recommendations for less invasive treatment, or a combination of both. We speculate a few reasons why this might be happening. Older patients with MCI might receive fewer treatments for AMI because physicians and patients overestimate their risk of dementia and underestimate their risk of CVD events, consistent with prior research showing that people tend to overestimate the likelihood of rare events and underestimate the likelihood of common events. ${ }^{45}$ In a community-based study of older adults with MCI, CVD caused $38 \%$ of deaths and dementia caused only $3 \%$ of deaths. ${ }^{11}$ Physicians and patients might conflate MCI with dementia, 5,6 and assume that a patient with MCI has a poor prognosis and limited life expectancy.

Physicians might recommend emergent, invasive treatments less frequently to patients with $\mathrm{MCI}$ owing to concerns 
about increased risk of treatment complications (e.g., delirium after $\mathrm{CABG}$ ) and decreased ability to understand invasive treatments, provide informed consent, and adhere to complex treatment regimens (e.g., dual antiplatelet therapy after PCI). Physicians might be unaware that a patient has MCI because $\mathrm{MCI}$ is underdiagnosed and poorly documented. ${ }^{46}$ So the HRS measure of MCI might be serving as a proxy for other patient factors (e.g., cognitive impairment, frailty, low health literacy) that, in turn, decrease physicians' recommendations for high intensity care. Our results suggest a scientific need to better understand decision-making for invasive but effective AMI treatments in older patients with MCI, the reasons for treatment differences, and methods to identify patients with $\mathrm{MCI}$ most likely to benefit from treatments.

More evidence on benefits and risks of AMI treatments in patients with MCI is also needed. However, it is important to note that we found no evidence that patients with MCI derive less survival benefit from coronary revascularization than cognitively normal patients. Our results show that preexisting MCI is associated with an increased risk of mortality and that receipt of coronary revascularization reduced this mortality risk, consistent with findings in patients with preexisting dementia. ${ }^{43}$ Studies also suggest that the risks and outcomes (cognition, mental functioning, physical functioning, and disease-specific quality of life) of AMI treatments, including revascularization, are similar between patients with MCI and cognitively normal patients. ${ }^{44,} 47$

Our study has several strengths. The HRS is a nationally representative study with rigorously collected data. The HRS's longitudinal, objective measurements of cognition ${ }^{26}$ before AMI hospitalization are a unique strength because cognitive function is not routinely collected in clinical practice and MCI is under-documented in administrative data. ${ }^{46}$ AMI has an identifiable time of diagnosis that is advantageous for studying serious illnesses in the elderly. ${ }^{35}$ We used a pre-specified analysis plan.

Our study has limitations. Our definition of MCI is based on a limited set of cognitive tests or proxy assessments without a full clinical evaluation, so misclassification is possible. The HRS is designed to measure MCI and dementia as accurately as possible with large-scale, nationally representative population surveys. The HRS approaches accurately classify $80-85 \%$ of HRS participants as having dementia versus no dementia (MCI or normal cognition) compared to the detailed neuropsychological and clinical assessments performed in the ADAMS study, the HRS dementia substudy. ${ }^{33,48}$ Although misclassifying patients with dementia as having MCI could bias our results away from the null, sensitivity analyses that further restricted the definition of MCI and excluded patients with potential dementia, based on CMS administrative data and IADL limitations, confirmed the robustness of our findings. The HRS method also accurately classifies $85-90 \%$ of HRS self-respondents as having normal cognition versus any cognitive impairment (MCI or dementia). ${ }^{33,34}$ Misclassifying cognitively normal patients as having MCI would reduce our ability to detect treatment differences by MCI status. Although we were unable to account for frailty ${ }^{49}$ because these data were unavailable for most patients (60\%), HRS participants classified as frail do not have greater prevalence of MCI compared to the overall study population, ${ }^{50}$ and we adjusted for functional limitations. We did not have information on AMI severity, delirium, or the appropriateness of the use of AMI treatments. It is possible that the effect size is exaggerated due to unmeasured confounding and small sample size.

The number of people diagnosed with $\mathrm{MCI}$ is expected to increase because the Affordable Care Act mandated coverage of an assessment of cognitive impairment as part of the annual wellness benefit for all Medicare beneficiaries. ${ }^{51}$ Older patients with $\mathrm{MCI}$, their care partners, and their physicians must weigh the risks and benefits of CVD treatments alongside competing risks (e.g., death and dementia). The care of CVD in older patients with MCI is crucial for elders $\geq 85$ because they comprise the fastestgrowing segment of the US population, ${ }^{52}$ they are most likely to have MCI, ${ }^{1}$ and their incidence of AMI has increased. ${ }^{53}$ The critical issue is that patients with $\mathrm{MCI}$ receive the care that they would want if properly informed. Despite clinical practice guidelines ${ }^{25}$ and the benefits on mortality and physical function, our results suggest that patients with MCI get coronary revascularization less often. Our results also suggest that cardiac rehabilitation remains underused in older adults with normal cognition or MCI. Given its benefits on mortality as well as physical function, efforts to improve the use of cardiac rehabilitation in both groups of older adults are warranted.

\section{CONCLUSIONS}

Pre-existing MCI was associated with lower likelihood of receiving cardiac catheterization and coronary revascularization but not cardiac rehabilitation after AMI.

Corresponding Author: Deborah A. Levine, MD, MPH; Department of Internal MedicineUniversity of Michigan (U-M), North Campus Research Complex, 2800 Plymouth Road, Building 16, Room 430W, Ann Arbor, MI 48109-2800, USA (e-mail: deblevin@umich.edu).

Funding This work was supported by NIH/NIA grant RO1 AG051827 (Levine DA, PI). The Health and Retirement Study is funded by the NIH/NIA (UO1 AGO09740) and performed at the Institute for Social Research, University of Michigan, Ann Arbor.

Dr. Levine was also supported by NINDS R01 NS102715 (PI) and was consultant/advisory board UCSF (event adjudicator for POINT trial). Dr. Langa received funding support from NIH/NIA grants P3O AG053760 and P3O AG024824. Dr. Galecki and M. Kabeto also received funding support from NIH/NIA grant P3O AG024824.

\section{Compliance with Ethical Standards:}

Conflict of Interest: The authors declare that they do not have a conflict of interest. 


\section{REFERENCES}

1. Plassman BL, Langa KM, Fisher GG, et al. Prevalence of cognitive impairment without dementia in the United States. Ann Intern Med 2008; 148(6):427-434.

2. Alzheimer's Association. 2014 Alzheimer's disease facts and figures. Alzheimers Dement 2014;10(2):e47-92.

3. Langa KM, Levine DA. The diagnosis and management of mild cognitive impairment: a clinical review. JAMA 2014;312(23):2551-2561.

4. Petersen RC. Clinical practice. Mild cognitive impairment. N Engl J Med 2011;364(23):2227-2234.

5. Knopman DS, Petersen RC. Mild cognitive impairment and mild dementia: a clinical perspective. Mayo Clin Proc 2014;89(10):1452-1459.

6. Graham JE, Rockwood K, Beattie BL, McDowell I, Eastwood R, Gauthier S. Standardization of the diagnosis of dementia in the Canadian Study of Health and Aging. Neuroepidemiology 1996;15(5):246-256.

7. Petersen RC, Caracciolo B, Brayne C, Gauthier S, Jelic V, Fratiglioni L. Mild cognitive impairment: a concept in evolution. J Intern Med 2014;275(3):214-228.

8. Farias ST, Mungas D, Reed BR, Harvey D, DeCarli C. Progression of mild cognitive impairment to dementia in clinic- vs community-based cohorts. Arch Neurol 2009;66(9):1151-1157.

9. Mitchell AJ, Shiri-Feshki M. Rate of progression of mild cognitive impairment to dementia-meta-analysis of 41 robust inception cohort studies. Acta Psychiatr Scand 2009;119(4):252-265.

10. Yaffe $\mathbf{K}$, Lindquist $\mathbf{K}$, Vittinghoff $\mathbf{E}$, et al. The effect of maintaining cognition on risk of disability and death. J Am Geriatr Soc 2010;58(5):889-894

11. Sachs GA, Carter R, Holtz LR, et al. Cognitive impairment: an independent predictor of excess mortality: a cohort study. Ann Intern Med 2011;155(5):300-308.

12. Barrios $\mathbf{H}$, Narciso $\mathbf{S}$, Guerreiro $\mathbf{M}$, Maroco $\mathbf{J}$, Logsdon $\mathbf{R}$, de Mendonca A. Quality of life in patients with mild cognitive impairment. Aging Ment Health 2013;17(3):287-292.

13. Ready RE, Ott BR, Grace J. Patient versus informant perspectives of Quality of Life in Mild Cognitive Impairment and Alzheimer's disease. Int J Geriatr Psychiatry 2004;19(3):256-265.

14. Benjamin EJ, Virani SS, Callaway CW, et al. Heart Disease and Stroke Statistics-2018 update: a report from the American Heart Association. Circulation 2018;137(12):e67-e492.

15. Saposnik G, Cote R, Rochon PA, et al. Care and outcomes in patients with ischemic stroke with and without preexisting dementia. Neurology 2011;77(18):1664-1673.

16. Sloan FA, Trogdon JG, Curtis LH, Schulman KA. The effect of dementia on outcomes and process of care for Medicare beneficiaries admitted with acute myocardial infarction. J Am Geriatr Soc 2004;52(2):173-181.

17. Murray CJ, Atkinsinson C, Bhalla $\mathbf{K}$, et al. The state of US health, 1990-2010: burden of diseases, injuries, and risk factors. JAMA: 2013;310(6):591-608.

18. Krumholz HM, Anderson JL, Bachelder BL, et al. ACC/AHA 2008 performance measures for adults with ST-elevation and non-STelevation myocardial infarction: a report of the American College of Cardiology/American Heart Association Task Force on Performance Measures (Writing Committee to Develop Performance Measures for STElevation and Non-ST-Elevation Myocardial Infarction) Developed in Collaboration with the American Academy of Family Physicians and American College of Emergency Physicians Endorsed by the American Association of Cardiovascular and Pulmonary Rehabilitation, Society for Cardiovascular Angiography and Interventions, and Society of Hospital Medicine. J Am Coll Cardiol. 2008;52(24):2046-2099.

19. Masoudi FA, Bonow RO, Brindis RG, et al. ACC/AHA 2008 statement on performance measurement and reperfusion therapy: a report of the ACC/AHA Task Force on Performance Measures (Work Group to address the challenges of performance measurement and reperfusion therapy). Circulation 2008;118(24):2649-2661.

20. Michels KB, Yusuf S. Does PTCA in acute myocardial infarction affect mortality and reinfarction rates? A quantitative overview (meta-analysis) of the randomized clinical trials. Circulation 1995;91(2):476-485.

21. Comparison of coronary bypass surgery with angioplasty in patients with multivessel disease. The Bypass Angioplasty Revascularization Investigation (BARI) Investigators. N Engl J Med. 1996;335(4):217-225.

22. Five-year clinical and functional outcome comparing bypass surgery and angioplasty in patients with multivessel coronary disease. A multicenter randomized trial. Writing Group for the Bypass Angioplasty Revascularization Investigation (BARI) Investigators. JAMA 1997;277(9):715-721.
23. Anderson L, Taylor RS. Cardiac rehabilitation for people with heart disease: an overview of Cochrane systematic reviews. Cochrane Database Syst Rev 2014;12:CD011273.

24. Dalal HM, Doherty P, Taylor RS. Cardiac rehabilitation. BMJ 2015;351.

25. Watson $\mathbf{K}$, Fung $\mathbf{C H}$, Budoff $\mathbf{M}$. Quality indicators for the care of ischemic heart disease in vulnerable elders. J Am Geriatr Soc 2007;55 Suppl 2:S366-372.

26. Sonnega A, Faul JD, Ofstedal MB, Langa KM, Phillips JW, Weir DR. Cohort Profile: the Health and Retirement Study (HRS). Int J Epidemiol 2014;43(2):576-585.

27. Lee DS, Stitt $\mathbf{A}$, Wang $\mathbf{X}$, et al. Administrative hospitalization database validation of cardiac procedure codes. Med Care 2013;51(4):e22-26.

28. Medicare. Your Medicare coverage. Cardiac rehabiliation programs. https: / /www.medicare.gov/coverage/cardiac-rehab-programs.html. Accessed 14 March 2019.

29. Plassman BL, Newman TT, Welsh KA, Helms M, Breitner JCS. Properties of the telephone interview for cognitive status-application in epidemiologic and longitudinal-studies. Neuropsychiatry Neuropsychol Behav Neurol 1994;7(3):235-241.

30. Welsh KA, Breitner JCS, Magruderhabib KM. Detection of dementia in the elderly using telephone screening of cognitive status. Neuropsychiatry Neuropsychol Behav Neurol 1993;6(2):103-110.

31. Langa KM, Larson EB, Karlawish JH, et al. Trends in the prevalence and mortality of cognitive impairment in the United States: is there evidence of a compression of cognitive morbidity? Alzheimers Dement 2008;4(2):134-144.

32. Langa KM, Plassman BL, Wallace RB, et al. The Aging, Demographics, and Memory Study: study design and methods. Neuroepidemiology 2005;25(4):181-191.

33. Crimmins EM, Kim JK, Langa KM, Weir DR. Assessment of cognition using surveys and neuropsychological assessment: the Health and Retirement Study and the Aging, Demographics, and Memory Study. J Gerontol Ser B Psychol Sci Soc Sci 2011;66 Suppl 1:i162-171.

34. Langa KM, Larson EB, Crimmins EM, et al. A Comparison of the prevalence of dementia in the United States in 2000 and 2012. JAMA Intern Med 2017;177(1):51-58.

35. Kelley AS. Epidemiology of care for patients with serious illness. J Palliat Med 2013;16(7):730-733

36. Piette JD, Rosland AM, Silveira M, Kabeto M, Langa KM. The case for involving adult children outside of the household in the self-management support of older adults with chronic illnesses. Chronic Illn 2010;6(1):3445.

37. Choi H, Schoeni RF, Langa KM, Heisler MM. Older adults' residential proximity to their children: changes after cardiovascular events. J Gerontol Ser B Psychol Sci Soc Sci 2015. 70(6):995-1004.

38. Choi H, Schoeni RF, Langa KM, Heisler MM. Spouse and child availability for newly disabled older adults: socioeconomic differences and potential role of residential proximity. J Gerontol Ser B Psychol Sci Soc Sci 2015;70(3):462-469.

39. Sobel M. In: S. L, ed. Sociological Methodology. San Francisco: JosseyBoss; 1982:290-312.

40. Lacobucci D. Mediation analysis and categorical variables: the final frontier. J Consum Psychol 2012;22(4):582-594.

41. Steinberg BA, French WJ, Peterson E, Frederick PD, Cannon CP, National Registry of Myocardial Infarction I. Is coding for myocardial infarction more accurate now that coding descriptions have been clarified to distinguish ST-elevation myocardial infarction from non-ST elevation myocardial infarction? Am J Cardiol 2008;102(5):513-517.

42. Yeh RW, Mauri L, Wolf RE, et al. Population trends in rates of coronary revascularization. JAMA Intern Med 2015;175(3):454-456.

43. Cermakova P, Szummer $\mathbf{K}$, Johnell $\mathbf{K}$, et al. Management of acute myocardial infarction in patients with dementia: data from SveDem, the Swedish Dementia Registry. J Am Med Dir Assoc 2017;18(1):19-23.

44. Gharacholou SM, Reid KJ, Arnold SV, et al. Cognitive impairment and outcomes in older adult survivors of acute myocardial infarction: findings from the translational research investigating underlying disparities in acute myocardial infarction patients' health status registry. Am Heart J 2011;162(5):860-869 e861.

45. Kahneman D. Thinking, Fast and Slow. New York: Farrar, Straus and Giroux; 2011.

46. Chodosh J, Petitti DB, Elliott M, et al. Physician recognition of cognitive impairment: evaluating the need for improvement. J Am Geriatr Soc 2004;52(7):1051-1059.

47. Trubnikova OA, Mamontova AS, Syrova ID, Maleva OV, Barbarash OL. Does preoperative mild cognitive impairment predict postoperative 
cognitive dysfunction after on-pump coronary bypass surgery? Journal of Alzheimer's Disease : JAD 2014;42 Suppl 3:S45-51.

48. Hurd MD, Martorell P, Delavande A, Mullen KJ, Langa KM. Monetary costs of dementia in the United States. N Engl J Med 2013;368(14):13261334.

49. Fried LP, Tangen CM, Walston $\mathbf{J}$, et al. Frailty in older adults: evidence for a phenotype. J Gerontol A Biol Sci Med Sci 2001;56(3):M146-156.

50. Cigolle CT, Ofstedal MB, Tian Z, Blaum CS. Comparing models of frailty: the Health and Retirement Study. J Am Geriatr Soc 2009;57(5):830-839.

51. The ABCs of the annual wellness visit. Medicare Learning Network educational tool. https://www.cms.gov/Outreach-and-Education/Medicare-Learning-Network-MLN/MLNProducts/downloads/AWV_chart ICN905706.pdf. Accessed 14 March 2019.
52. Federal Interagency Forum on Aging-Related Statistics. Older Americans 2016: key indicators of well-being. Federal Interagency Forum on AgingRelated Statistics. Washington, DC: U.S. Government Printing Office; 2016. Available at: https://agingstats.gov/docs/latestreport/older-americans-2016-key-indicators-of-wellbeing.pdf. Accessed 14 March 2019.

53. Shroff GR, Heubner BM, Herzog CA. Incidence of acute coronary syndrome in the general medicare population, 1992 to 2009: a realworld perspective. JAMA Intern Med 2014;174(10):1689-1690.

Publisher's Note Springer Nature remains neutral with regard to jurisdictional claims in published maps and institutional affiliations. 